\title{
Cultivo sucessivo de plantas de tomate oriundas de sementes e propagação vegetativa em sistema hidropônico
}

\author{
Adriano Alves Fernandes ${ }^{(1)}$, Herminia Emilia Prieto Martinez $z^{(1)}$, Derly José Henriques da Silva ${ }^{(1)}$, \\ José Geraldo Barbosa ${ }^{(1)}$ e Adriene Woods Pedrosa ${ }^{(1)}$
}

\begin{abstract}
(1)Universidade Federal de Viçosa, Dep. de Fitotecnia, Av. P.H. Rolfs, s/no, CEP 36570-000 Viçosa, MG. E-mail: afer03@yahoo.com.br, herminia@ufv.br, derly@ufv.br, jgeraldo@ufv.br, awoodsp@yahoo.com.br
\end{abstract}

\begin{abstract}
Resumo - O objetivo deste trabalho foi avaliar as posições de origem de estacas de tomateiro na planta matriz, e quantificar a produtividade e qualidade dos frutos do híbrido Carmen, propagado por estaquia, em quatro cultivos sucessivos, o primeiro proveniente de sementes e os demais de estacas. Avaliaram-se produção por planta, massa dos frutos, número de frutos por planta, teor de sólidos solúveis, porcentagem de ácido cítrico e nutrientes em folhas e frutos. Os cultivos foram propagados, vegetativamente, em esquema fatorial $3 \times 2$ (três cultivos sucessivos e duas posições de origem das estacas, ápice e base), em blocos ao acaso, e parcelas subdivididas no tempo, com seis repetições. Compararam-se os quatro cultivos sucessivos, com base no intervalo de confiança das médias obtidas para as características avaliadas. A propagação vegetativa não reduziu a produtividade e a qualidade dos frutos, independentemente da posição de origem das estacas usadas nos três cultivos sucessivos. Também não foram observadas diferenças na produção e qualidade dos frutos, quando comparados o cultivo proveniente de sementes e os três oriundos de propagação vegetativa.
\end{abstract}

Termos para indexação: Lycopersicon esculentum, solução nutritiva, hidroponia.

\section{Successively cultivated tomato plants originated from seeds and vegetative propagation in hydroponic system}

\begin{abstract}
The objective of this work was to evaluate the origin positions of tomato plant cuttings in the main plant, and to quantify the production and quality of fruits of tomato plants vegetatively propagated, in four successive cultivations, the first one originated from seeds, and the three subsequent ones from cuttings. Data evaluated were: production of fruits per plant; fruit weight; number of fruits per plant; soluble solids; citric acid; and leave and fruit macro and micronutrients contents. The experimental design was in randomized blocks, in a factorial scheme $3 \times 2$ (three cuttings plants cultivations $\times 2$ cuttings' origin positions), with splitplot in time, and six replicates. The cultivations were compared based on the confidence interval of the mean for each evaluated characteristic. The vegetative propagation did not reduce productivity and fruit quality, independently of the cuttings' origin positions used in the three subsequent cultivations. Either for plant production and fruit quality there were no significant differences among cultivations originated from seed or vegetatively propagated.
\end{abstract}

Index terms: Lycopersicon esculentum, nutritive solution, hydroponic.

\section{Introdução}

O tomate é consumido tanto in natura como na forma de produtos processados pela indústria, portanto, é uma das principais hortaliças consumidas no mundo, com grande importância econômica. Em 2005, o Brasil destacou-se como o nono produtor mundial de tomate, com produção de cerca de 3,2 milhões de toneladas, em aproximadamente 61 mil hectares (Agrianual, 2006).

A cultura do tomateiro é considerada atividade de alto risco, principalmente pela grande susceptibilidade ao ataque de pragas e doenças, oscilações nos preços de mercado e grande exigência de insumos e serviços. Os altos custos de implementação e manutenção da cultura estimulam a busca de condições mais favoráveis no interior de estufas, isto possibilita maior e melhor controle da temperatura e umidade relativa e, conseqüentemente, dos tratos fitossanitários e do fornecimento de água e nutrientes, o que minimiza os riscos e favorece o aumento da produtividade e da qualidade dos frutos (Guimarães, 1999). 
Alguns trabalhos realizados têm associado o cultivo protegido, o sistema hidropônico e a produção de tomates com apenas um cacho, visando otimizar as condições favoráveis (Logendra \& Janes, 1999; Fernandes, 2000; Okano et al., 2000; Sakamoto et al., 2000; Fernandes et al., 2002). O cultivo do tomateiro, com apenas um cacho por planta, reduz o ciclo da cultura expondo-a a menores riscos de ataques por pragas e doenças e, associado à redução do espaçamento, resulta em um sistema altamente produtivo. Além disso, em hidroponia, o manejo adequado das concentrações de nutrientes da solução nutritiva, como o aumento da relação $\mathrm{K} / \mathrm{N}$, na fase de frutificação (Adams, 1994), permite obter frutos de melhor qualidade (Fernandes, 2000). Logendra \& Janes (1999) relatam, também, como vantagens desse sistema, a melhor utilização de luz suplementar, fácil acesso para manuseio das plantas (podas, desbastes de frutos, pulverização, polinização e colheita) e aumento da eficiência de trabalho pela automatização e escalonamento das colheitas. $O$ custo inicial de implantação e a necessidade de mão de obra qualificada podem ser desvantagens desse sistema.

Fernandes et al. (2002) observaram, em um sistema hidropônico, o potencial vegetativo do tomateiro com um cacho, e constataram a ocorrência de grande número de brotações, o que demonstra, portanto, que a propagação vegetativa é viável. Contudo, não se têm, ainda, estimativas da produtividade de plantas oriundas desse tipo de propagação. Tal informação é importante, uma vez que o método de estaquia pode propiciar redução no custo de produção e viabilizar o cultivo hidropônico de tomateiro com um cacho, principalmente quando são considerados os novos híbridos no mercado.

A propagação vegetativa do tomateiro é uma das alternativas para se reduzir os custos de produção de mudas, e a estaquia é a técnica de maior viabilidade econômica para o estabelecimento de plantios clonais, por permitir a multiplicação de genótipos selecionados, em curto período de tempo, a um menor custo. A estaquia consiste em destacar da planta matriz um ramo, uma folha ou raiz e em colocá-lo em meio adequado, para que enraíze ou desenvolva parte aérea (Hartmann et al., 1997).

O objetivo deste trabalho foi avaliar as posições de origem das estacas de tomateiro na planta matriz, e quantificar a produtividade e a qualidade dos frutos do híbrido Carmen, propagado por estaquia, em quatro cultivos sucessivos, o primeiro proveniente de sementes e os demais de estacas.

\section{Material e Métodos}

Foram realizados quatro cultivos sucessivos de tomate longa vida, híbrido Carmem, nos períodos de 12/12/2002 a 19/2/2003, 20/1/2003 a 6/4/2003, 18/3/2003 a 16/6/2003 e $7 / 6 / 2003$ a 31/8/2003, respectivamente. O meio de cultivo constituiu-se de um sistema hidropônico NFT (nutrient film technique), em casa de vegetação, na Universidade Federal de Viçosa. O cultivo inicial constituiu-se de mudas originadas de sementes, e os três cultivos posteriores constituíram-se de mudas provenientes de estacas, retiradas sempre do cultivo anterior, considerado como matriz.

No primeiro cultivo, as sementes germinaram em espuma fenólica; foram irrigadas, nos 10 primeiros dias, com água deionizada e, posteriormente, com solução nutritiva de crescimento vegetativo (Tabela 1) com 50\% de força iônica. As irrigações foram ministradas uma vez ao dia, após as 18h, para menor evapotranspiração, em volume suficiente para saturar o substrato. Após 30 dias, as mudas foram transferidas para o sistema NFT.

As mudas foram colocadas em bancadas, dispostas em blocos ao acaso, na casa de vegetação. Cada bancada (parcela experimental) foi composta por quatro canais de polipropileno, com $75 \mathrm{~mm}$ de largura e $2 \mathrm{~m}$ de comprimento, que comportavam 30 plantas espaçadas entre si de $0,25 \times 0,25 \mathrm{~m}$. Os dois canais laterais, bem como as plantas das extremidades dos canais foram considerados bordadura, o que resultou em 10 plantas úteis por parcela experimental. Foram estabelecidas seis repetições.

Tabela 1. Soluções nutritivas de crescimento vegetativo e frutificação, utilizadas no cultivo do tomateiro, híbrido Carmen, em sistema hidropônico.

\begin{tabular}{lcr}
\hline Fertilizante & Crescimento vegetativo & Frutificação \\
& ------- & 173,7 \\
$\mathrm{H}_{3} \mathrm{PO}_{4}$ & 115,8 & 369,6 \\
$\mathrm{MgSO}_{4}$ & 246,4 & 587,8 \\
$\mathrm{KNO}_{3}$ & 427,3 & 631,6 \\
$\mathrm{Ca}\left(\mathrm{gO}_{3}\right)_{2}$ & 389,3 & 241,8 \\
$\mathrm{CaCl}_{2}$ & 33,1 & 15,9 \\
$\mathrm{FeCl}_{3}$ & 9,6 & 20,0 \\
$\left.\mathrm{Na}_{2}-\mathrm{EDTA}^{-1}\right)$ & 13,2 & 5,5 \\
$\mathrm{MnSO}_{4}$ & 3,7 & 1,9 \\
$\mathrm{H}_{3} \mathrm{BO}_{3}$ & 1,3 & 1,3 \\
$\mathrm{ZnSO}_{4}$ & 1,3 & 0,2 \\
$\mathrm{NaMoO}_{4}$ & 0,2 & 0,2 \\
$\mathrm{CuSO}_{4}$ & 0,1 &
\end{tabular}

Fonte: Fernades et al. (2002). 
Empregou-se solução nutritiva de crescimento vegetativo até o aparecimento dos frutos e, em seguida, solução nutritiva de frutificação (Tabela 1). $\mathrm{O}$ fornecimento da solução foi realizado de forma intermitente, com $15 \mathrm{~min}$ de fornecimento e $15 \mathrm{~min}$ de intervalo entre 6 e $20 \mathrm{~h}$. Durante a noite, procedeu-se a cinco ciclos de irrigação de $30 \mathrm{~min}$ em intervalos regulares. $\mathrm{O}$ pH e a condutividade elétrica (CE) da solução nutritiva foram monitorados diariamente. Sempre que necessário, o $\mathrm{pH}$ foi ajustado para a faixa entre 5,5 e 6,5. A concentração de nutrientes da solução nutritiva foi mantida, com base na CE inicial, tendo-se admitido depleção máxima de $30 \%$. A condutividade elétrica inicial foi de $1,14 \mathrm{dS} \mathrm{m}^{-1}$, para a fase de crescimento vegetativo, e de $2,50 \mathrm{dS} \mathrm{m}^{-1}$, para a fase de frutificação. As temperaturas máximas e mínimas no interior da estufa foram registradas diariamente. As plantas foram conduzidas com um cacho com no máximo seis frutos, e a poda apical foi realizada duas folhas acima do cacho.

Nomomentoda colheitado primeiro frutomaduro, foi colhida a folha imediatamente abaixo do cacho, para determinação de macro e micronutrientes. Foram colhidos, ainda, dois frutos por repetição, um no início e outro no final da colheita, para a determinação de macro e micronutrientes em frutos. Todos os frutos tiveram seu diâmetro medido, tendo-se calculado o porcentual de frutos gigantes (diâmetro $>100 \mathrm{~mm}$ ), grandes (diâmetro de 80-100 mm), médios (diâmetro de 65-80 mm), pequenos (diâmetro de 50-65 mm) e desclassificados (diâmetro de $<50 \mathrm{~mm}$ ), segundo portaria do Ministério da Agricultura Pecuária e Abastecimento (Fontes \& Silva, 2002). Avaliaramse, também, a duração do ciclo (dias), a produção de frutos (gramaporplanta), opesodos frutos (grama por fruto), odiâmetro dos frutos (mm) e o número de frutos por planta.

Tanto em folhas quanto em frutos, os elementos $\mathrm{P}, \mathrm{K}, \mathrm{Ca}$, $\mathrm{Mg}, \mathrm{S}, \mathrm{Fe}, \mathrm{Mn}, \mathrm{Zn}$ e $\mathrm{Cu}$ foram analisados, após a mineralização, pela digestão nítrico-perclórica, eo P foi dosado por colorimetria (Braga \& Defelipo, 1974); o K foi determinado em fotometria de emissão de chama; o $\mathrm{Ca}$, $\mathrm{Mg}, \mathrm{Fe}, \mathrm{Mn}, \mathrm{Zn}$ e $\mathrm{Cu}$ foram determinados por espectrofotometria de absorção atômica; e o $\mathrm{S}$ foi determinado por turbidimetria do sulfato (Balanchar et al., 1965). O N-NH${ }_{4}^{+}$foi obtido pelo método de Nessler, após digestão sulfúrica (Jackson, 1958), e o N-NO ${ }_{3}^{-}$pelo método de Cataldo, após extração com água quente (Cataldo et al., 1975). O nitrogênio total foi obtido pela soma das concentrações de $\mathrm{N}-\mathrm{NH}_{4}{ }^{+}$e $\mathrm{N}-\mathrm{NO}_{3}{ }^{-}$. Nos frutos, determinaram-se, também, os sólidos solúveis totais (SST) por refratometria, e a porcentagem de ácido cítrico pelo método gravimétrico do Instituto Adolfo Lutz (1985).
No primeiro cultivo, denominado sementes, as plantas foram divididas em duas partes para a retirada de estacas. O ponto de divisão foi na terceira folha, abaixo do primeiro cacho, e, abaixo dessa posição, foram consideradas estacas da base, e acima estacas do ápice. As estacas foram coletadas, quando atingiram comprimento de 15 a $20 \mathrm{~cm}$, com no máximo três folhas (com comprimento acima de $2 \mathrm{~cm}$ ), e foram transferidas para vasos de $9 \mathrm{~L}$ de capacidade, onde foram enraizadas diretamente em solução nutritiva de crescimento vegetativo, com $50 \%$ de força iônica. Após 20 dias, as mudas enraizadas foram transplantadas para o sistema NFT. No segundo cultivo, denominado estacas 1 , uma metade das parcelas recebeu plantas oriundas de estacas retiradas da base da planta, e outra metade recebeu estacas do ápice da planta.

Foram realizadas seis repetições para cada tratamento (estacas do ápice e estacas da base), e as técnicas de cultivo e avaliações foram as mesmas descritas para o primeiro cultivo. No cultivo estacas 1 , foram retiradas estacas apicais e basais para o cultivo denominado estacas 2. No cultivo denominado estacas 2, foram retiradas estacas apicais e basais para o cultivo subseqüente, denominado estacas 3. Os cultivos estacas 2 e 3 foram conduzidos e avaliados da mesma maneira que o estacas 1 .

Os dados obtidos foram submetidos a diferentes tratamentos estatísticos. Primeiramente, os dados referentes aos três cultivos de estacas foram analisados, tendo-se considerado a origem das estacas na planta matriz, ápice e base. O esquema de análise constituiu-se de um fatorial $2 \times 3$ ( 2 posições de origem das estacas e 3 cultivos sucessivos), com parcelas subdivididas no tempo, em blocos ao acaso e com seis repetições. As comparações entre tratamentos foram realizadas pelo teste de Tukey, a $5 \%$ de probabilidade.

Como não houve efeito significativo da posição de retirada das estacas, os dados também foram analisados por meio de estatística descritiva, tendo-se desconsiderado a origem das estacas e comparado os quatro cultivos sucessivos entre si. Os tratamentos foram sementes, estacas 1, estacas 2 e estacas 3. Calcularam-se para todas as características e cultivos, as médias $(\bar{y})$, os desvios-padrão da média ( $\mathrm{S} \bar{y})$, e os intervalos de confiança das médias IC $=\bar{y} \pm \mathrm{t} \alpha \mathrm{S} \bar{y}$, em que: $\bar{y}$ é a média da característica; $\mathrm{S} \bar{y}$ é o desvio-padrão da média; $\mathrm{e}$ t $\alpha$ é o valor de $\mathrm{t}$ bilateral a $5 \%$ de probabilidade com $\mathrm{n}-1$ repetições. As diferenças entre os tratamentos foram consideradas significativas, quando não houve intersecção entre os intervalos de confiança. 


\section{Resultados e Discussão}

A produção de frutos por planta, número de frutos por cacho, massa e diâmetro de frutos não variaram entre os cultivos estacas 1, estacas 2 e estacas 3 . As médias de produção de frutos por planta $(569 \mathrm{~g})$, massa dos frutos $(113 \mathrm{~g})$ e diâmetro dos frutos $(62,2 \mathrm{~mm})$ foram menores que as observadas por Fernandes et al. (2002), para híbrido Carmem, cultivado com um cacho em hidroponia, que corresponderam a $920 \mathrm{~g} ; 155 \mathrm{~g} \mathrm{e} 71,2 \mathrm{~mm}$, respectivamente. A média para número de frutos por planta foi de 5 .

Não foram observadas, também, diferenças para origem das estacas. Plantas originárias de estacas do ápice ou da base, na média dos três cultivos, produziram $569 \mathrm{~g}$ de frutos por planta. Os frutos apresentavam $62,4 \mathrm{~mm}$ de diâmetro e pesavam $114 \mathrm{~g}$, para plantas originárias de estacas do ápice, e $62 \mathrm{~mm}$ e $112 \mathrm{~g}$, para plantas originárias de estacas da base. Tais resultados demonstram a possibilidade de uso de estacas do ápice ou base da planta matriz.

A produção de frutos por planta resultou em valores semelhantes, na comparação dos quatro cultivos. As médias observadas para os tratamentos sementes, estacas 1, 2 e 3 foram 583, 584, 562 e $561 \mathrm{~g}$ (Tabela 2), o que corresponderia a 93,2, 93,4, 89,9 e 89,8 $\mathrm{tha}^{-1}$, respectivamente. Considerando-se que os ciclos dos cultivos foram de $69,76,90$ e 85 dias, obtém-se produtividade acumulada de $366,6 \mathrm{t} \mathrm{ha}^{-1}$, em 320 dias.

$\mathrm{O}$ valor médio de produção de frutos por planta (572 g), nos 4 cultivos, foi menor que as $920 \mathrm{~g}$ por planta obtidas por Fernandes et al. (2002). A diferença entre esses resultados pode ser atribuída à densidade de plantio que, no presente trabalho, foi de 16 plantas $\mathrm{m}^{-2}$, enquanto no trabalho desses autores foi de 4 plantas $\mathrm{m}^{-2}$. Quanto à produção de frutos, por unidade de área, tem-se uma inversão desses valores, em que as produtividades estimadas seriam correspondentes a $91,6 \mathrm{t} \mathrm{ha}^{-1} \mathrm{e}$ $37,6 \mathrm{tha}^{-1}$, respectivamente, para ambos os trabalhos. Segundo Morgan (1996), o cultivo do tomateiro com um cacho, em densidades entre $10 \mathrm{e} 16$ plantas $\mathrm{m}^{-2}$, tem como objetivo aumentar o número de ciclos por ano, com aumento na eficiência de produção. Andriolo \& Falcão (2000) recomendam para o cultivo do tomateiro o uso de altas densidades de plantas desfolhadas, como alternativa para maximizar o rendimento de frutos por unidade de área cultivada.

Houve diferença significativa entre os cultivos quanto à massa dos frutos. A massa dos frutos do tratamento estacas 2 (119 $\mathrm{g}$ por fruto) foi semelhante à massa dos frutos dos tratamentos estacas 1 (112 g por fruto) e 3 (108 g por fruto), e superior à massa dos frutos do tratamento sementes $(103 \mathrm{~g}$ por fruto) (Tabela 2). A massa dos frutos dos tratamentos sementes, estacas 1 e 3 foi semelhante entre si.

Não foi observada diferença significativa, entre os cultivos, quanto ao diâmetro dos frutos. Entretanto, com a sucessão de cultivos, a quantidade de frutos com diâmetro menor que $50 \mathrm{~mm}$ (desclassificados) aumentou de 4,9 para 15,7\%, entre os tratamentos sementes e estacas 3. Esse fato ocorreu paralelo à redução de 69,8 para $44,9 \%$, no porcentual de frutos com diâmetro entre 50 e $65 \mathrm{~mm}$; aumento de 25,3 a $36,4 \%$, nas porcentagens dos frutos médios ( $>65$ até $80 \mathrm{~mm}$ ), e de 0 a $3,2 \%$ nos grandes ( $>80$ até $100 \mathrm{~mm}$ ), nos tratamentos sementes a estacas 3 , respectivamente. No entanto, não se pode creditar tais diferenças à sucessão de cultivos de propagação vegetativa, pois a temperatura mínima média reduziu-se de $20,2^{\circ} \mathrm{C}$ para

Tabela 2. Produção de frutos por planta, massa dos frutos, diâmetro dos frutos, número de frutos por planta, sólidos solúveis totais e ácido cítrico em frutos de tomateiros cultivados em hidroponia, propagados sucessivamente por sementes, estacas 1, estacas 2 e estacas $3^{(1)}$.

\begin{tabular}{|c|c|c|c|c|c|c|c|c|}
\hline \multirow[t]{2}{*}{ Variável } & \multicolumn{2}{|c|}{ Sementes } & \multicolumn{2}{|c|}{ Estacas 1} & \multicolumn{2}{|c|}{ Estacas 2} & \multicolumn{2}{|l|}{ Estacas 3} \\
\hline & Valores & $\mathrm{CV}(\%)$ & Valores & $\mathrm{CV}(\%)$ & Valores & $\mathrm{CV}(\%)$ & Valores & $\mathrm{CV}(\%)$ \\
\hline Produção de frutos (grama por planta) & $582,68 \pm 41,31$ & 6,76 & $583,9 \pm 73,57$ & 12,00 & $562,03 \pm 91,69$ & 15,55 & $561,29 \pm 124,15$ & 21,08 \\
\hline Massa dos frutos (grama por fruto) & $103,02 \pm 4,43$ & 4,10 & $111,73 \pm 6,62$ & 5,64 & $118,86 \pm 6,47$ & 5,19 & $107,77 \pm 16,44$ & 14,54 \\
\hline Diâmetro dos frutos (mm) & $61,54 \pm 2,12$ & 3,29 & $62,53 \pm 1,60$ & 2,44 & $63,10 \pm 1,58$ & 2,39 & $61,08 \pm 4,29$ & 6,70 \\
\hline Número de frutos por planta & $5,66 \pm 0,33$ & 5,52 & $5,21 \pm 0,53$ & 9,75 & $4,74 \pm 0,60$ & 12,05 & $5,16 \pm 0,51$ & 9,45 \\
\hline Sólidos solúveis totais (\%) & $4,78 \pm 0,11$ & 2,17 & $5,0 \pm 0,23$ & 4,29 & $4,91 \pm 0,22$ & 4,18 & $4,46 \pm 0,52$ & 11,08 \\
\hline Ácido cítrico (\%) & $0,46 \pm 0,03$ & 6,78 & $0,52 \pm 0,06$ & 11,39 & $0,54 \pm 0,05$ & 9,54 & $0,58 \pm 0,13$ & 20,83 \\
\hline
\end{tabular}

${ }^{(1)}$ Estacas 1: plantas oriundas de estacas retiradas da base e ápice das plantas do tratamento sementes; estacas 2: plantas oriundas de estacas retiradas da base e ápice das plantas do tratamento estacas 1; estacas 3: plantas oriundas de estacas retiradas da base e ápice das plantas do tratamento estacas 2; IC $=\bar{y} \pm$ t $\alpha \mathrm{S} \bar{y}$; t $\alpha$ é o valor de t bilateral a 5\% de probabilidade, com $\mathrm{n}$ - 1 repetições; nas linhas, as médias que apresentam interseção entre os intervalos de confiança são consideradas semelhantes a $5 \%$ de probabilidade. 
$11,6^{\circ} \mathrm{C}$, entre o primeiro e o último cultivo. De acordo com Andriolo \& Falcão (2000), a baixa fração da matéria seca alocada em frutos, nas culturas de outono conduzidas em estufas no Sul do Brasil, pode relacionar-se ao efeito negativo das baixas temperaturas noturnas sobre o transporte de fotoassimilados das folhas para os frutos.

Em relação ao número de frutos por planta, não foi observada diferença significativa entre os cultivos. As médias variaram de 4,7 a 5,7 (Tabela 2). Esperava-se, em conseqüência do hábito de crescimento indeterminado do híbrido, que as plantas apresentassem o mínimo de seis frutos por cacho. Camargos (1998) observou que a redução de espaçamento de 60 para $30 \mathrm{~cm}$, entre plantas do híbrido Carmem, cultivado com seis frutos por cacho, proporcionou redução no número de flores e frutos eliminados, o que sustenta a hipótese de que o número de frutos por cacho pode ser limitado pelo adensamento de plantas.

Não foi observada, também, diferença significativa entre os cultivos, quanto ao teor de sólidos solúveis totais (SST) e concentração de ácido cítrico nos frutos. Para SST, as médias variaram de 4,5 a 5\%, e para ácido cítrico, entre 0,46 e $0,58 \%$. Cecon Novo (2002), Fernandes et al. (2002) e Calimam (2003) também obtiveram faixas de valores semelhantes para SST, com o híbrido Carmem: 3,6 a 5,2; 4,5 a 5,2 e 4,8 a 5,4 respectivamente. Para ácido cítrico, Cecon Novo (2002) encontrou teores entre 0,46 e $0,59 \%$. O teor de sólidos solúveis é fator importante na avaliação da qualidade de fruto, pois representa o equilíbrio entre ácidos e açúcares solúveis. Frutos com valores de porcentagem de sólidos solúveis acima de cinco são considerados de maior qualidade (Morgan, 1997). Altas concentrações de açúcares e ácidos são requeridas, para melhor sabor dos frutos do tomateiro, e o ácido cítrico é mais importante do que o ácido málico (Grierson \& Kader, 1986).

Quanto aos teores foliares de nutrientes, não foram observadas diferenças significativas entre os cultivos para o $\mathrm{N}$ total, $\mathrm{NO}_{3}{ }^{-}, \mathrm{Ca}$, e Zn (Tabela 3). A concentração de $\mathrm{N}$ total variou de 27,3 a $35,4 \mathrm{~g} \mathrm{~kg}^{-1}$, próxima à faixa de concentração de 28 a $60 \mathrm{~g} \mathrm{~kg}^{-1}$, considerada adequada por Jones Junior (1999) e, também, aos valores de 36,2 a $39,9 \mathrm{~g} \mathrm{~kg}^{-1}$ obtidos por Camargos (1998), com espaçamento de 30 a $60 \mathrm{~cm}$ entre plantas e 3 a 7 cachos por planta. As concentrações foliares de $\mathrm{NO}_{3}{ }^{-}$variaram de 1,8 a $2,2 \mathrm{~g} \mathrm{~kg}^{-1}$. Cecon Novo (2002) trabalhou com o mesmo híbrido, cultivado em solo e em casa de vegetação, e obteve valores de concentração de $\mathrm{NO}_{3}{ }^{-}$entre 2,8 e $4,7 \mathrm{~g} \mathrm{~kg}^{-1}$. Tais resultados indicam que, para o tomateiro, a hipótese do acúmulo de $\mathrm{NO}_{3}{ }^{-}$, em plantas cultivadas em sistema hidropônico, não se sustenta.

Para o Ca e Zn, foram observados teores foliares de 38,7 a 43,4 $\mathrm{g} \mathrm{kg}^{-1} \mathrm{e} 32$ a $51 \mathrm{mg} \mathrm{kg}^{-1}$, respectivamente (Tabela 3). Jones Junior (1999) considera adequados teores entre $9 \mathrm{e}$ $72 \mathrm{~g} \mathrm{~kg}^{-1}$, para o Ca, e 20 e $100 \mathrm{mg} \mathrm{kg}^{-1}$, para o Zn. Cecon Novo (2002) obteve valores de concentrações de Zn entre 30 e $66 \mathrm{mg} \mathrm{kg}^{-1}$, em folhas desse mesmo híbrido, cultivados em solo e em casa de vegetação.

Para as concentrações foliares de $\mathrm{P}, \mathrm{K}, \mathrm{Mg}, \mathrm{S}, \mathrm{B}, \mathrm{Cu}$, $\mathrm{Fe}$ e $\mathrm{Mn}$, foram observadas diferenças significativas entre os cultivos (Tabela 3), provavelmente em razão das variações na qualidade dos diferentes lotes de

Tabela 3. Concentrações de macronutrientes e micronutrientes em folhas de tomateiros cultivados em hidroponia e propagados, sucessivamente, por sementes, estacas 1 , estacas 2 e estacas $3^{(1)}$.

\begin{tabular}{|c|c|c|c|c|c|c|c|c|}
\hline \multirow[t]{2}{*}{ Nutriente } & \multicolumn{2}{|c|}{ Sementes } & \multicolumn{2}{|c|}{ Estacas 1} & \multicolumn{2}{|c|}{ Estacas 2} & \multicolumn{2}{|c|}{ Estacas 3} \\
\hline & Concentrações & $\mathrm{CV}(\%)$ & Concentrações & $\mathrm{CV}(\%)$ & Concentrações & $\mathrm{CV}(\%)$ & Concentrações & $\mathrm{CV}(\%)$ \\
\hline $\mathrm{N}$ total $\left(\mathrm{g} \mathrm{kg}^{-1}\right)$ & $35,41 \pm 1,98$ & 5,34 & $27,26 \pm 10,21$ & 35,69 & $30,76 \pm 4,77$ & 14,78 & $34,09 \pm 5,38$ & 15,03 \\
\hline $\mathrm{N}-\mathrm{NO}_{3}{ }^{-}\left(\mathrm{g} \mathrm{kg}^{-1}\right)$ & $1,90 \pm 0,35$ & 17,55 & $2,19 \pm 0,63$ & 27,32 & $2,00 \pm 0,52$ & 24,73 & $1,81 \pm 0,29$ & 15,06 \\
\hline $\mathrm{P}\left(\mathrm{g} \mathrm{kg}^{-1}\right)$ & $3,82 \pm 0,26$ & 6,48 & $3,30 \pm 0,35$ & 10,13 & $3,14 \pm 0,37$ & 11,20 & $5,04 \pm 0,43$ & 8,15 \\
\hline $\mathrm{K}\left(\mathrm{g} \mathrm{kg}^{-1}\right)$ & $46,88 \pm 5,52$ & 11,22 & $49,00 \pm 5,03$ & 9,78 & $42,87 \pm 3,31$ & 7,35 & $38,22 \pm 4,07$ & 10,16 \\
\hline $\mathrm{Ca}\left(\mathrm{g} \mathrm{kg}^{-1}\right)$ & $42,39 \pm 2,76$ & 6,21 & $39,68 \pm 3,38$ & 8,13 & $43,43 \pm 5,21$ & 11,43 & $43,32 \pm 10,13$ & 22,28 \\
\hline $\operatorname{Mg}\left(\mathrm{g} \mathrm{kg}^{-1}\right)$ & $8,78 \pm 0,71$ & 7,72 & $7,40 \pm 0,74$ & 9,53 & $8,0 \pm 0,49$ & 5,86 & $9,96 \pm 1,37$ & 13,08 \\
\hline $\mathrm{S}\left(\mathrm{g} \mathrm{kg}^{-1}\right)$ & $8,29 \pm 0,54$ & 6,24 & $7,16 \pm 0,41$ & 5,41 & $9,33 \pm 1,77$ & 18,07 & $11,89 \pm 3,21$ & 25,73 \\
\hline $\mathrm{Fe}\left(\mathrm{mg} \mathrm{kg}^{-1}\right)$ & $157,08 \pm 23,95$ & 14,54 & $166,80 \pm 15,54$ & 8,88 & $244,43 \pm 62,15$ & 24,23 & $302,95 \pm 58,02$ & 18,25 \\
\hline $\mathrm{B}\left(\mathrm{mg} \mathrm{kg}^{-1}\right)$ & $202,26 \pm 30,48$ & 14,36 & $119,92 \pm 23,69$ & 18,83 & $112,82 \pm 24,06$ & 20,33 & $139,10 \pm 24,96$ & 17,10 \\
\hline $\mathrm{Cu}\left(\mathrm{mg} \mathrm{kg}^{-1}\right)$ & $30,30 \pm 7,31$ & 22,98 & $7,32 \pm 1,61$ & 20,99 & $8,20 \pm 2,00$ & 23,29 & $32,97 \pm 9,70$ & 28,03 \\
\hline $\mathrm{Zn}\left(\mathrm{mg} \mathrm{kg}^{-1}\right)$ & $41,98 \pm 9,61$ & 21,83 & $32,02 \pm 7,26$ & 21,63 & $49,28 \pm 14,19$ & 27,44 & $51,22 \pm 22,29$ & 41,48 \\
\hline $\operatorname{Mn}\left(\mathrm{mg} \mathrm{kg}^{-1}\right)$ & $657,13 \pm 198,20$ & 28,75 & $431,58 \pm 79,28$ & 17,51 & $1.072,79 \pm 261,49$ & 23,23 & $740,50 \pm 219,6$ & 28,28 \\
\hline
\end{tabular}

${ }^{(1)}$ Estacas 1: plantas oriundas de estacas retiradas da base e ápice das plantas do tratamento sementes; estacas 2: plantas oriundas de estacas retiradas da base e ápice das plantas do tratamento estacas 1; estacas 3: plantas oriundas de estacas retiradas da base e ápice das plantas do tratamento estacas 2; IC $=\bar{y} \pm \mathrm{t} \alpha \mathrm{S} \bar{y}$; t $\alpha$ é o valor de t bilateral a 5\% de probabilidade, com $\mathrm{n}$ - 1 repetições; nas linhas, as médias que apresentam interseção entre os intervalos de confiança são consideradas semelhantes a $5 \%$ de probabilidade. 
fertilizantes empregados, ou mesmo da composição da água. O cultivo estacas 3 apresentou concentrações superiores de $\mathrm{P}, \mathrm{Mg}, \mathrm{S}, \mathrm{Cu}$ e $\mathrm{Fe}$, o que poderia ser atribuído a um efeito de concentração, uma vez que a produção de matéria seca, à época do ano em que o cultivo foi conduzido, estaria limitada pelas baixas temperaturas mínimas noturnas.

As concentrações foliares de $\mathrm{P}, \mathrm{K}, \mathrm{Mg}, \mathrm{S}, \mathrm{B}, \mathrm{Cu}, \mathrm{Fe}$ e Mn, observadas nos quatro cultivos (Tabela 3), variaram dentro de faixas semelhantes às obtidas por Fernandes et al. (2002) e Cecon Novo (2002), e das consideradas adequadas por Jones Junior (1999), para o tomateiro, à exceção das concentrações de B (113 a $202 \mathrm{mg} \mathrm{kg}^{-1}$ ) e Mn (432 a $1.073 \mathrm{mg} \mathrm{kg}^{-1}$ ), que se apresentaram elevadas e chegaram, no caso do Mn, ao limite de toxidez indicado por Adams (1986). Por essa razão, ainda que as concentrações de $\mathrm{B}$ e Mn, utilizadas na solução nutritiva, sejam consideradas adequadas para o tomateiro, e que o desempenho das plantas tenha sido adequado, seria recomendável reduzi-las na solução de frutificação de Fernandes et al. (2002).

Em frutos, exceto para $\mathrm{Mg}$ e $\mathrm{Zn}$, todos os nutrientes analisados apresentaram variação significativa entre cultivos, e não foi possível estabelecer relações de causa e efeito, muito embora se possa observar que, de modo geral, o cultivo sementes e estacas 3 apresentaram maiores concentrações (Tabela 4).

Os elementos presentes em maior quantidade, nos frutos do tomateiro, foram o K, N e P (Tabela 4), que representaram mais de $90 \%$ de seu conteúdo total em minerais, resultado esse de acordo com o observado por Davis \& Hobson (1981). Entre estes, o K representou cerca de $60 \%$ do total. O K proporciona aumento de produção, contribui para a melhoria da qualidade comercial dos frutos e reduz sua queda, durante os estádios de formação e amadurecimento (Alvarenga, 2000), e a qualidade dos tomates cultivados em hidroponia é dependente da adequação da concentração de $K$ na solução nutritiva, a partir do início da frutificação (Adams, 1994). Nessa fase, a relação $\mathrm{N}: \mathrm{K}$ absorvidos, altera-se drasticamente, e é necessário o aumento do suprimento de $\mathrm{K}$, para garantir a qualidade e uniformidade da maturação dos frutos (Ho \& Adams, 1995).

Quanto ao $\mathrm{Ca}$, os valores obtidos são próximos à faixa de concentração de 1,4 a 1,5 g kg-1, obtida por Fernandes et al. (2002), para a região do fruto próxima ao pedúnculo. O Ca é fundamental na nutrição do tomateiro, e sua carência contribui para que ocorra podridão apical ou estilar dos frutos (Alvarenga, 2000), o que prejudica a comercialização. A incidência de podridão apical aumenta significativamente, quando a concentração de Ca no fruto é menor que $0,8 \mathrm{~g} \mathrm{~kg}^{-1}$, e raramente ocorre, quando a concentração é maior que $1,2 \mathrm{~g} \mathrm{~kg}^{-1}$ (Grierson \& Kader, 1986).

Quanto aos micronutrientes, o Fe foi o que apresentou as maiores concentrações nos frutos, enquanto as menores concentrações foram as de $\mathrm{Cu}$. Apesar das altas concentrações de B e Mn, observadas nas folhas, nos frutos as concentrações desses elementos mantiveram-se baixas (Tabela 4).

Tabela 4. Concentrações de macronutrientes e micronutrientes em frutos de tomateiros cultivados em hidroponia e propagados, sucessivamente, por sementes, estacas 1 , estacas 2 e estacas $3^{(1)}$.

\begin{tabular}{|c|c|c|c|c|c|c|c|c|}
\hline \multirow[t]{2}{*}{ Nutriente } & \multicolumn{2}{|c|}{ Sementes } & \multicolumn{2}{|c|}{ Estacas 1} & \multicolumn{2}{|c|}{ Estacas 2} & \multicolumn{2}{|c|}{ Estacas 3} \\
\hline & Concentrações & $\mathrm{CV}(\%)$ & Concentrações & $\mathrm{CV}(\%)$ & Concentrações & $\mathrm{CV}(\%)$ & Concentrações & $\mathrm{CV}(\%)$ \\
\hline $\mathrm{N}$ total $\left(\mathrm{g} \mathrm{kg}^{-1}\right)$ & $26,53 \pm 3,77$ & 13,56 & $23,99 \pm 1,91$ & 7,59 & $19,94 \pm 1,30$ & 6,21 & $22,84 \pm 2,54$ & 10,61 \\
\hline $\mathrm{N}-\mathrm{NO}_{3}^{-}\left(\mathrm{g} \mathrm{kg}^{-1}\right)$ & $0,40 \pm 0,03$ & 71,12 & $0,90 \pm 0,04$ & 49,74 & $1,10 \pm 0,01$ & 13,20 & $1,20 \pm 0,03$ & 23,31 \\
\hline $\mathrm{P}\left(\mathrm{g} \mathrm{kg}^{-1}\right)$ & $2,97 \pm 0,21$ & 6,62 & $2,75 \pm 0,11$ & 3,73 & $2,23 \pm 0,17$ & 7,07 & $2,82 \pm 0,25$ & 8,32 \\
\hline $\mathrm{K}\left(\mathrm{g} \mathrm{kg}^{-1}\right)$ & $50,70 \pm 6,24$ & 11,74 & $42,87 \pm 2,84$ & 6,33 & $40,12 \pm 2,88$ & 6,83 & $42,66 \pm 4,10$ & 9,15 \\
\hline $\mathrm{Ca}\left(\mathrm{g} \mathrm{kg}^{-1}\right)$ & $1,41 \pm 0,25$ & 17,22 & $1,44 \pm 0,34$ & 22,47 & $1,89 \pm 0,28$ & 14,23 & $2,03 \pm 0,33$ & 15,66 \\
\hline $\operatorname{Mg}\left(\mathrm{g} \mathrm{kg}^{-1}\right)$ & $1,93 \pm 0,34$ & 17,00 & $1,67 \pm 0,14$ & 7,81 & $1,60 \pm 0,15$ & 8,76 & $1,75 \pm 0,15$ & 8,31 \\
\hline $\mathrm{S}\left(\mathrm{g} \mathrm{kg}^{-1}\right)$ & $1,68 \pm 0,13$ & 7,58 & $1,59 \pm 0,11$ & 6,66 & $1,51 \pm 0,21$ & 13,24 & $2,17 \pm 0,26$ & 11,42 \\
\hline $\mathrm{Fe}\left(\mathrm{mg} \mathrm{kg}^{-1}\right)$ & $73,87 \pm 14,09$ & 18,18 & $126,61 \pm 80,82$ & 60,84 & $48,73 \pm 7,07$ & 13,83 & $85,02 \pm 10,70$ & 11,99 \\
\hline $\mathrm{B}\left(\mathrm{mg} \mathrm{kg}^{-1}\right)$ & $34,58 \pm 7,30$ & 20,11 & $31,84 \pm 15,88$ & 47,53 & $22,76 \pm 4,51$ & 18,90 & $20,12 \pm 8,60$ & 40,59 \\
\hline $\mathrm{Cu}\left(\mathrm{mg} \mathrm{kg}^{-1}\right)$ & $4,57 \pm 0,77$ & 16,10 & $6,93 \pm 0,55$ & 7,56 & $3,98 \pm 2,08$ & 50,07 & $6,83 \pm 1,61$ & 22,51 \\
\hline $\mathrm{Zn}\left(\mathrm{mg} \mathrm{kg}^{-1}\right)$ & $20,71 \pm 6,86$ & 31,55 & $17,98 \pm 1,87$ & 9,90 & $14,51 \pm 5,42$ & 35,63 & $14,89 \pm 2,26$ & 14,48 \\
\hline $\operatorname{Mn}\left(\mathrm{mg} \mathrm{kg}^{-1}\right)$ & $22,90 \pm 4,27$ & 17,79 & $28,68 \pm 3,64$ & 12,11 & $32,48 \pm 7,45$ & 21,87 & $41,60 \pm 6,34$ & 14,52 \\
\hline
\end{tabular}

(1)Estacas 1: plantas oriundas de estacas retiradas da base e ápice das plantas do tratamento sementes; estacas 2: plantas oriundas de estacas retiradas da base e ápice das plantas do tratamento estacas 1; estacas 3: plantas oriundas de estacas retiradas da base e ápice das plantas do tratamento estacas 2; IC $=\bar{y} \pm \mathrm{t} \alpha \mathrm{S} \bar{y}$; t $\alpha$ é o valor de $\mathrm{t}$ bilateral a $5 \%$ de probabilidade, com $\mathrm{n}$ - 1 repetições; nas linhas, as médias que apresentam interseção entre os intervalos de confiança são consideradas semelhantes a $5 \%$ de probabilidade. 


\section{Conclusões}

1. O uso de mudas propagadas vegetativamente, no cultivo hidropônico do tomateiro, é viável, e podem ser utilizadas estacas provenientes do ápice ou da base da planta matriz.

2. Com relação à produtividade, qualidade dos frutos e teores de nutrientes minerais em folhas e frutos, não há diferenças entre os três cultivos sucessivos de tomateiros propagados por estaquia, nem entre estes e o cultivo por mudas provenientes de sementes.

\section{Agradecimentos}

À Coordenação de Aperfeiçoamento de Pessoal de Nível Superior (Capes), por concessão de bolsa.

\section{Referências}

ADAMS, P. Mineral nutrition. In: ATHERTON, J.G.; RUDICH, J. The tomato crop: a scientific basis for improvement. London: Chapmam and Hall, 1986. p.281-334.

ADAMS, P. Nutrition of greenhouse vegetables in NFT and hydroponic systems. Acta Horticulturae, n.361, p.245-257, 1994.

ALVARENGA, M.A.R. Cultura do tomateiro. Lavras: UFLA, 2000. 91p.

ANDRIOLO, J.L.; FALCÃO, L.L. Efeito da poda de folhas sobre a acumulação de matéria seca e sua repartição para os frutos do tomateiro cultivado em ambiente protegido. Revista Brasileira de Agrometeorologia, v.8, p.75-83, 2000.

BLANCHAR, R.W.; REHM, G.; CALDWELL, A.C. Sulfur in plant material by digestion with nitric and perchloric acid. Proceedings of Soil Science Society of America, v.29, p.71-72, 1965.

BRAGA, J.M.; DEFELIPO, B. Determinação espectrofotométrica de fósforo em extratos de solos e plantas. Revista Ceres, v.21, p.73-85, 1974.

CALIMAM, F.R.B. Produção e qualidade de frutos de genótipos de tomateiro em ambiente protegido e no campo. 2003. 72p. Dissertação (Mestrado) - Universidade Federal de Viçosa, Viçosa.

CAMARGOS, M.I. Produção e qualidade de tomate longa vida em estufa, em função do espaçamento e do número de cachos por planta. 1998. 68p. Dissertação (Mestrado) - Universidade Federal de Viçosa, Viçosa.

CATALDO, D.A.; HAROON, M.; SCHRADER, L.E.; YOUNGS, V.L. Rapid colorimetric determination of nitrate in plant tissue by nitrification of salicylic acid. Communications in Soil Science and Plant Analysis, v.6, p.71-80, 1975.

CECON NOVO, A. Avaliação do sistema fito 2 na produção de tomate longa vida em casa de vegetação. 2002. 70p. Dissertação (Mestrado) - Universidade Federal de Viçosa, Viçosa.
DAVIS, J.N.; HOBSON, G.E. The constituents of tomato fruit: the influence of environment, nutrition, and genotype. Critical Reviews in Food Science and Nutrition, v.15, p.205-280, 1981.

FERNANDES, A.A. Fontes de nutrientes influenciando o crescimento, a produtividade e a qualidade de tomate, pepino e alface, cultivados em hidroponia. 2000. 75p. Dissertação (Mestrado) - Universidade Federal de Viçosa, Viçosa.

FERNANDES, A.A.; MARTINEZ, H.E.P.; FONTES, P.C.R. Produtividade, qualidade dos frutos e estado nutricional do tomateiro tipo longa vida conduzido com um cacho, em cultivo hidropônico, em função das fontes de nutrientes. Horticultura Brasileira, v.20, p.564570, 2002.

FONTES, P.C.R.; SILVA, D.J.H. da. Produção de tomate de mesa. Viçosa: UFV, 2002. 196p.

GUIMARÃES, T.G. Nitrogênio no solo e na planta, teor de clorofila e produção do tomateiro, no campo e na estufa, influenciado por doses de nitrogênio. 1999. 184p. Tese (Doutorado) - Universidade Federal de Viçosa, Viçosa.

GRIERSON, D.; KADER, A.A. Fruit ripening and quality. In.: ATHERTON, J.G. The tomato crop: a scientific basis for improvement. London: Chapman and Hall, 1986. p.241-280.

HARTMANN, H.T.; KESTER, D.E.; DAVIES JUNIOR, F.T.; GENEVE, R.L. Plant propagation: principles and practices. $6^{\text {th }}$ ed. New Jersey: Prentice Hall International, 1997. 770p.

HO, L.C.; ADAMS, P. Nutrient uptake and distribution in relation to crop quality. Acta Horticulturae, n.396, p.33-44, 1995.

INSTITUTO FNP. Agrianual 2006: anuário da agricultura brasileira. São Paulo: FNP Consultoria \& Comércio, 2006. 504p.

JACKSON, M.L. Nitrogen determinations for soil and plant tissue. In: JACKSON, M.L. (Ed.). Soil chemical analysis. Englewood Chiffis: Prentice-Hall, 1958. p.183-204.

JONES JUNIOR, J.B. Tomato plant culture in the field, greenhouse, and home garden. Florida: CRC Press. 1999. 199p.

LOGENDRA, L.S.; JANES, H.W. Hydroponic tomato production: growing media requirements. Acta Horticulturae, v.2, p.483-486, 1999.

MORGAN, L. Hydroponic fruit quality testing. Practical Hydroponics and Greenhouses, n.34, p.21-31, 1997.

MORGAN, L. Single truss tomato production in NFT systems. Practical Hydroponics and Greenhouses, n.31, p.42-47, 1996.

OKANO, K.; SAKAMOTO, Y.; WATANABE, S. Reuse of drainage water for the production of high quality fruits in single-truss tomato grown in a closed hydroponic system. Acta Horticulturae, n.511, p.277-286, 2000.

MORGAN, L. Single truss tomato production in NFT systems. Practical Hydroponics and Greenhouses, n.31, p.42-47, 1996.

PREGOLATTO, W.; PREGOLATO, D.P. Normas analíticas do Instituto Adolfo Lutz. 3.ed. São Paulo: Instituto Adolfo Lutz, 1985. 375p.

SAKAMOTO, Y.; WATANABE, S.; OKANO, K. Multi-shoot training in single-truss tomato cultivation. Bulletin of the National Research Institute of Vegetables, Ornamental Plants and Tea, v.15, p.115-122, 2000. 